\title{
Open-Source ERP: Is It Ripe for Use in Teaching Supply Chain Management?
}

\author{
Minh Q Huynh, Ph.D. \\ Department of Marketing \& \\ Supply Chain Management \\ Southeastern Louisiana \\ University, Hammond, LA, USA
}

\author{
Hung W Chu, Ph.D. \\ Department of Management \\ Baruch College, \\ New York, NY, USA
}

\author{
minh.huynh@selu.edu
}

hung.chu@baruch.cuny.edu

\section{Executive Summary}

The field of supply chain management has changed greatly and rapidly. With the advent of enterprise systems, supply chains are now operating with up-to-the-minute information. The value of the information flow is marked by speed, accessibility, accuracy, and most of all relevancy. As it continually evolves, the supply chain management curriculum needs to stay current and relevant. This paper advocates the use of technology such as Enterprise Resource Planning (ERP) to teach business process integration. The literature review indicates a number of significant benefits when firms use ERP. For instance, an ERP system can help firms manage their assets and operate their internal business processes more effectively and efficiently. It has the ability to coordinate a complex network of sub-processes to achieve the goals of the organization. This paper describes the needs for teaching business process integration and stresses the roles of ERP in a supply chain process. It then presents two approaches: the SAP University Alliances program and the opensource ERP option. To illustrate the potential of open-source ERP, the discussion focuses on one particular application called xTuple-PostBooks. What is xTuple-PostBooks? How can one obtain it? What is involved in its installation and setup? How is it used in teaching and illustrating business process integration? What was the students' feedback?

xTuple-PostBooks is developed by xTuple as an open-source ERP. It can be downloaded at no cost. This paper describes an actual experience of how xTuple was installed on Ubuntu operation system and how it was used to teach students in two university MIS courses. One of the interesting observations is that the user communities from Ubuntu and xTuple are very helpful and the useful resources are readily accessible. This marks a significant maturity in open-source software in general. After the students learned the conceptual knowledge of ERP, they began to use xTuple-PostBooks in a series of hands-on sessions. Students had an opportunity to observe and actu-

Material published as part of this publication, either on-line or in print, is copyrighted by the Informing Science Institute. Permission to make digital or paper copy of part or all of these works for personal or classroom use is granted without fee provided that the copies are not made or distributed for profit or commercial advantage AND that copies 1) bear this notice in full and 2) give the full citation on the first page. It is permissible to abstract these works so long as credit is given. To copy in all other cases or to republish or to post on a server or to redistribute to lists requires specific permission and payment of a fee. Contact Publisher@,InformingScience.org to request redistribution permission. ally try out how one transaction could trigger multiple operations and link them all together within a typical business process. At the end of the semester, each student filled out a survey to provide feedback on his/her experience with xTuple-PostBooks. The majority of the students perceived that xTuplePostBooks met their requirements and they were satisfied with xTuplePostBooks. The conclusion of the paper 
highlights the feasibility of xTuple-PostBooks to be used as a teaching tool, the shared experience from this paper to reduce its learning curve, and the potential for xTuple-PostBooks to be used as a bridge for partnership with small and mid-sized organizations. Finally, the paper offers practical implications as well as discusses the limitations and direction for future work.

Keywords: Open-source ERP, xTuple, xTuple-PostBooks, teach business process integration, supply chain management.

\section{Introduction}

During the 1990s, it took an average of fifteen to thirty days for a company to take an order, process it, and deliver a finished product to a customer from a warehouse in the United States, but companies operating at that level would not survive today's competition. In the current global economy, companies must innovate in order to stimulate growth and remain competitive (Léger, Charland, Feldstein, Robert, Babin, \& Lyle, 2011). Supply chains are operating on the basis of up-to-the-minute information. The value of the information flow is marked by speed, accessibility, accuracy, and most of all relevancy. The most noticeable innovative technology that transformed the management of supply chain is the advancement of enterprise systems such as Enterprise Resource Planning (ERP).

The emergence of the Internet, evolving customer demands, the pressure to accelerate the business process, and the need to establish more collaborative relationships with key suppliers and business partners are pushing organizations large and small towards the use of an ERP solution. There is a constant need to integrate information systems within core business processes of the enterprise, and of course the introduction of new technologies into the workplace (Kesner, 2008). To prepare and educate managers to lead future organizations, it is imperative not only to teach them conceptual knowledge about integrated business processes, but also to allow them to develop hands-on skills in adopting, deploying, and actually using the technologies that drive business process integration.

While it is recognized that the use of ERP systems might provide a variety of benefits in a business school curriculum, how can business schools continue to maintain their technology-based curriculum given limited resources during the recent economic downturn? This is a challenge facing business schools around the country. In this paper, we attempt to explore and present a possible solution to this challenge through our own experience in the adoption and use of an opensource ERP rather than the traditional proprietary ERP solution. The key issue is whether or not an open-source ERP is ripe for use in teaching courses related to supply chain management and business integration.

The paper is organized into four sections. The first section provides the background for this study by describing the importance of ERP in supply chain management and the needs for its use in teaching business integration. The second section presents the description of two approaches: the traditional SAP University Alliances Model vs. the open-source alternative. It is followed by an in-depth report of our experiences with xTuple-PostBooks, the open-source ERP that we adopted and used to teach our classes. The final part of the paper features the discussion, conclusion, practical implications, limitations, and our thoughts for further related work.

\section{Review of the Background for this Study}

\section{The Use of ERP in Facilitating Supply Chain Management}

There are a number of reasons and benefits for firms to use ERP. An ERP system can help firms manage their assets and operate their internal business processes more effectively and efficiently. 
More importantly, ERP can provide firms with access to valuable information along those boundaries and interaction points that occur between the firms and their customers and suppliers (Caruso, 2009). A well-designed ERP can be used to effectively and efficiently manage the company's supply chain. A supply chain can simply be characterized as an inter-organizational process that monitors and controls the flow of materials from production of raw materials to the final sales of a finished product. At the core of the supply chain is the ability to coordinate and manage a complex network of sub-processes to achieve the goals of the organization.

In his 2009 article entitled " 4 ways an integrated ERP system improves supply chain performance," Caruso identified the following:

- An ERP system allows firms to develop better customer insight because it provides a holistic view of customers to help firms better understand their customers and thus differentiate their offerings.

- It enables businesses to achieve global visibility in a demand-driven supply chain by providing critical information of when and where inventory is throughout the entire supply chain.

- It provides companies the ability to set up lean operations, global sourcing, and supplier integration by providing real-time production data exchange with suppliers.

- It helps organizations to achieve higher profitability by including business analytics to enable executives to standardize metrics and monitor production and performance.

Therefore, firms that use an integrated ERP to facilitate supply chain management can reap the benefits of cost structure reduction, shortened response time, and improved transparency. In turn, such benefits can lead to better customer satisfaction and higher profitability for these firms. In sum, ERP is one of the key information resources that can help firms streamline and enhance their supply chains and gain a competitive edge.

\section{The Need for Teaching Business Process Integration with ERP}

For many years business educators have stressed the need for a curriculum change that will allow graduates to learn and to understand an integrated business processes (Porter \& McKibbin, 1988). The need to teach business graduates the challenges and impact of these integrated systems has been repeatedly expressed in both professional and academic literature (Hawking, McCarthy, \& Stein, 2004; Peslak, 2005; Seethamraju, 2007). Being taught by the traditional view of seeing procurement, manufacturing, and distribution as distinctive functions, many students often have trouble in seeing how different processes from various functions are linked together to form an integrated enterprise system. Most of the world's largest organizations have already adopted an ERP system and, so, have a growing number of small and mid-sized organizations around the world (Léger et al., 2011). The effective use of ERP systems by many organizations to integrate their business processes suggests that a demonstration of ERP application software can be a good experience for students to gain an understanding of key business processes and the practice of cross-functional integration. In this respect, using ERP software might provide a missing link that could be used as an integrating mechanism in business college curricula (Hawking, Bassett, \& Foster, 2002; Johnson, Lorents, Morgan, \& Ozmum, 2004). Furthermore, with a proper implementation, it can serve as an effective vehicle to facilitate changes from functional perspectives to business process-oriented perspectives not only in a traditional classroom but also in an elearning course (Hawking \& McCarthy, 2004). This is the reason many business schools might desire to teach ERP and, in many cases, to use it as a mechanism for business curriculum integration (Andriole \& Roberts 2008; Hawking et al., 2002; Hayes \& McGilsky, 2007; Lee, Chen, \& Yang, 2006; Madapusi, 2007; Wang \& El-Masry, 2009; Winkelmann \& Leyh, 2010). 
The following sections present two choices for integrating an ERP into a business curriculum. The first uses a commercially available software package exemplified by the SAP University Alliances model, and the second uses an open-source ERP application.

\section{Proprietary Model vs. Open-Source Alternative}

\section{Traditional SAP University Alliances Model}

For those who teach business process integration, the SAP University Alliances model is not new. The SAP software company started this program over a decade ago. In the early years, the program was costly and difficult to install. The installation required the following resources: an annual fee, ERP software, a database management system, a server, an Internet connection, time and cost of training, and support. This totaled to at least $\$ 50,000$ to start up. Today, the cost to join SAP University Alliance has dropped significantly. The fee is $\$ 8000$ per year paid directly to one of the two hosting centers: University of Wisconsin, Milwaukee or California State University of Chico. There is a discount for the first year member with free four months. The $\$ 8000$ fee covers the following:

- Access to SAP software with no additional charge because SAP donates its software licensing to the SAP services center for teaching at no cost.

- Access to a rich portfolio of curriculum materials and teaching aids with no additional charge. These materials, including cases, projects, exercises, labs, and presentations, have been developed by faculty for teaching purpose.

- Attendance of faculty workshops at no cost except for the travel expenses. These workshops are mainly for training purposes.

- Opportunity to participate at academic events for collaboration and exchange of ideas.

- Access to the University Alliance community portal. This is a one-stop place where users can get support from the community, download videos, look at the library, and explore different curriculum materials contributed by peers.

- Membership into American SAP Users Group.

With over a decade of experience, the SAP University Alliances have continued to evolve, grow, and improve. SAP claims to have over two million SAP Community Network members. Among them are 200,000 SAP University Alliances Community members. SAP's strong presence in academia can be seen with over 1,000 University Alliances member schools. Its membership includes universities from the United States as well as those from different countries.

According to the University Alliances Program: Bird's Eye View of UA in North America (Corbitt \& Matthews, 2009), the program aims at providing university faculty members with the tools and resources necessary to teach students about SAP. The effort is to provide students with realtime access and first-hand experience in using their ERP system, one of the most dominant products in the market. Through the process of learning SAP's ERP, students may be able to acquire not only practical skills in using the software but also a deeper understanding of the complex integrated business processes as well as strategic thinking. Today's installation of the SAP system has been streamlined greatly. The program members can gain access to the SAP Business Suite through valuable services including hosting services, curriculum support, faculty training, access to the Innovation Watch Web site, as well as collaboration.

\section{SAP business suite}

Enabled by service-oriented architecture (SOA), Business Suite 7 is the latest bundle of SAP's main enterprise applications, including SAP ERP, SAP Customer Relationship Management, 
SAP Supplier Relationship Management, SAP Supply Chain Management and SAP Product Lifecycle Management. The company has made improvements to each of the applications included in the bundle that are largely dependent on the department or process being served. SAP's Business Suite 7 with its service-oriented architecture (SOA) is aimed at giving the user a richer, more seamless experience in using various components, including ERP and CRM applications.

\section{Different ways to use SAP's ERP software}

Member schools may use the software in a variety of ways. One option is to focus on executing transactions to use the ERP system to show how information flows as in the order-to-cash or purchasing processes. The other option is to use the system to generate enterprise-level reporting and illustrate how different sources of data can be integrated, processed, and analyzed. Another option is to focus on technical aspects of SAP such as systems administration, configuration and implementation courses, or developer/programming courses. Most recently, some schools have used an integrated business case in which students may view a business from a variety of perspectives such as using the same case study and data in supply chain, accounting, and/or HR classes.

\section{Steps to join the Alliances}

The first step for the prospective member campus is the development of a curriculum plan. The purpose of this plan is to outline a business case for incorporating the SAP products into the educational undertakings at that campus. SAP will supply the campus with a curriculum planning guide that helps guide the discussion among interested faculty so they can decide how to incorporate SAP software products into their specific school curriculum. The planning process helps build the faculty team, get administration buy-in, and develop the funding strategy with corporate partners. The process is iterative, and the guidelines are intended to initiate and structure the process rather than define the final output. The next step is to begin the process of installation and deployment (Corbitt \& Matthews, 2009). For more information about SAP University Alliances

program and how to join it, readers are encouraged to contact innovation.watch@sap.com or visit http://www.sdn.sap.com/irj/uac/overview.

SAP University Alliances program offers a valuable tool to help universities facilitate the learning and understanding of business processes through a widely used package and at the same time help students gain a valuable skill in ERP. This program provides rich resources with more than a decade of operation. The existing resources can help one to start using SAP in a relatively short time. There is no need to reinvent what others have done. Hence, time saving is perhaps one of the main attractions of the SAP University Alliances Model. However, the cost to join the program, though having decreased in recent years, remains an inhibitive factor for many universities that are struggling with limited resources and budgets.

\section{The Open-Source ERP Alternative}

In the midst of the current global economic crisis, business schools around the country are facing greater demands for academic enhancement while the resources to meet those needs are dwindling. With less resource available, the open-source ERP has been looked at increasingly as an alternative to the commercially available ERP software package.

\section{Open source software}

Open-source software refers to computer software that is developed and distributed under an open-source license. Such a license allows free access to the source code and imposes no license fee. Anyone can study, change, and improve the software for distribution. In recent years, opensource software has been increasingly recognized and eagerly embraced by businesses and or- 
ganizations interested in an alternative to proprietary software. Its wide adoption has been in part fueled by the availability of successful and popular software such as Linux, Ubuntu, the Firefox web browser, OpenOffice suite, MySQL, PostgreSQL, and, most importantly, the web server software Apache (Conlon, 2007; Conlon \& Hulick, 2006).

\section{Open source ERP}

Despite the growth of open-source software popularity, the open-source ERP is not well known. Its availability remains limited. At the present time, there are only a handful of open-source ERP vendors. Among the best-known are Apache OFBiz, Compiere, Openbravo, and xTuple.

Although open-source ERP packages are still in their infancy, their potential growth is quite promising due to the impact of the recent economic downturn. The reason is that many companies are under pressure to streamline their operations for efficiency and to reduce costs. As they reassess their information systems costs, they are attracted to open-source software because of the lack of license fees and recent enhancements. Since open-source ERP was developed under the open-source license terms, the cost to acquire the software is perceived to be minimal. On the contrary, the commercial ERP is costly because buyers have only two choices: SAP or Oracle. The buyers have little leverage in controlling their overall costs that do not include just the initial purchase of license and setup but also costly support and maintenance agreements (Lemos, 2008). On the other hand, the open-source ERP solutions allow anyone to view, audit, change, and distribute the source code freely. This is a significant breakthrough in the market that is dominated by mainly the proprietary software from SAP and Oracle. Since ERP systems often require a great deal of customization, having an open-source ERP seems like a good fit (Lemos, 2008).

\section{Our Experiences with xTuple-PostBooks}

In this paper, we chose xTuple-PostBooks as our open source ERP platform. Our purpose here is not to promote xTuple-PostBooks over other products or to make any claims on the merit of xTuple-PostBooks. Our intention is mainly to share what we have learned through our trial of xTuplePostbooks and to provide some insights that may help guide those interested in choosing and assessing it as an alternative to SAP.

The reasons for our decision to work with xTuple-PostBooks are simple. One, xTuple-PostBooks is free for download and use because it is open source software. Two, the demo and documentation on xTuple-PostBooks are readily available and very detailed, making it easy to learn and to try out. Finally, there is a wealth of support that was accessible directly from the menu of xTuplePostBooks including "Community" forum, FAQ page, and references.

\section{About xTuple Company and its Products}

OpenMFG began its development in 2000 and later changed its name to xTuple. xTuple markets its ERP systems to small and medium enterprises (SME) and manufacturers in particular. Two of its commercial products are xTuple ERP Manufacturing Edition and Standard Edition. These two products were developed and sold based on the "community code" model, where the code was not made publicly available, but was accessible only to those customers who purchased or subscribed to licenses. More details on the history and product detail are available from the company's website http://www.xtuple.com/postbooks

\section{Registering and Using a Hosted Demo of xTuple Manufacturing Edition}

To allow prospective buyers a chance to experience with its product, xTuple offers a free hosted demo of its flagship Manufacturing Edition. After registration, we were able to test the applica- 
tion. This demo walks one through a basic business process flow. All the data are already in the system. Users just need to follow a series of related screenshots.

\section{Installing and Using the Free xTuple PostBooks Edition}

After testing out the hosted demo, we decided to download and install the open-source version the PostBook Edition, which is available at SourceForge. We installed it on a server running Ubuntu. Since the details on how to install and set up xTuple-PostBooks Edition is beyond the scope of this paper, we simply provide this URL http://cob.gss.selu.edu/xTuple/doc/installation/ where our installation steps and setup notes are presented in detail for reference.

When we did our installation and setup, we encountered a few difficulties. However, we posted our questions to the xTuple user community forum as well as the Ubuntu community support. We got helpful hints and suggestions from other users. The resources from the user community are surprisingly rich and quite accessible. This user driven support is perhaps one of the distinctive features of open-source software and is a very effective way to get help. After we successfully installed and set up xTuple-PostBooks on our own server, we began to use it in classes.

\section{Using xTuple-PostBooks in Classes}

At the initial stage of our implementation, our goals for using xTuple-PostBooks were two-fold. First, we hoped to demonstrate the capability of an actual ERP system rather than just reading it from the textbook. Our other goal was to allow students an opportunity to work on an ERP through a business process example.

We used xTuple-PostBooks in two classes at our university: one upper-level MIS course and one MBA-level MIS course. The use of xTuple-PostBooks was integrated in the section where enterprise systems were introduced. We gave students a reading on ERP and also had one class discussion on issues related to ERP. In the next class, we demonstrated xTuple-PostBooks and gave them some basic training on the interface and the technology behind it. In the third class, we had a lab session in which students had an opportunity to log on the xTuple-PostBooks server from their laptop computers.

The following is a short description of steps in this lab session to illustrate how a business process is integrated with xTuple-PostBooks and is handled by various modules in xTuple-PostBooks. The visual representation of this process was captured in Figure 1 to show this particular sequence of transactions triggered by a sales order.

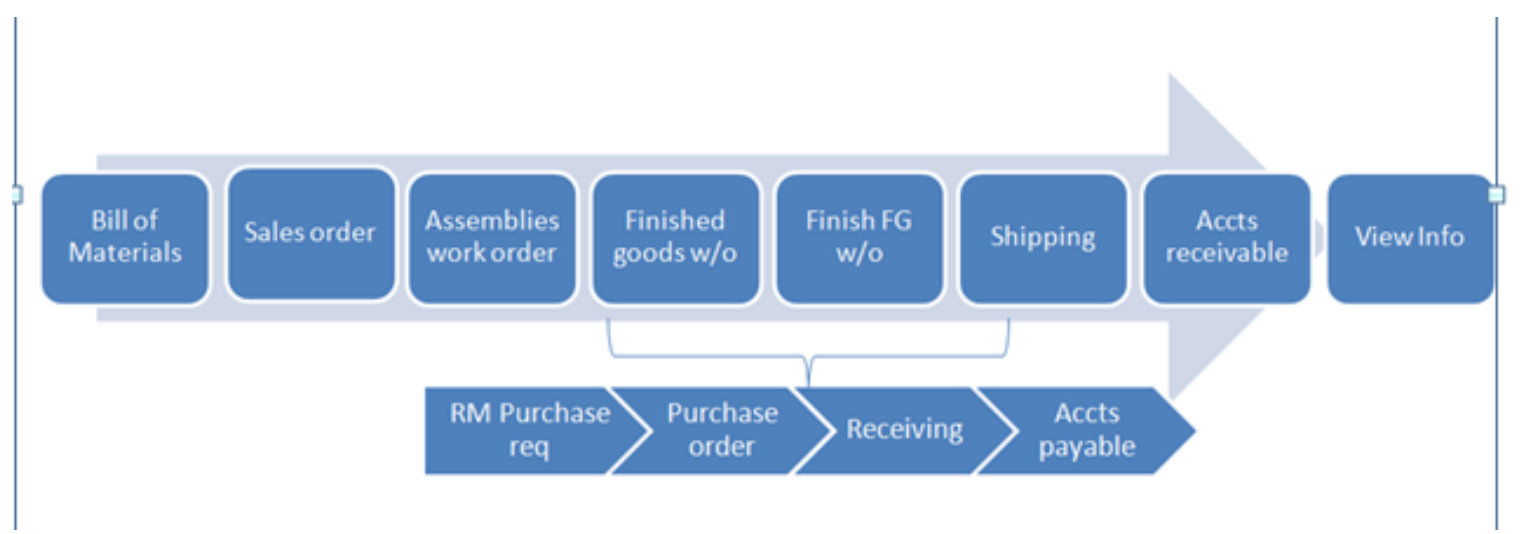

Figure 1: Sequence of Transactions Triggered by a Sales Order 
To start the lab, we created records for Indented Bill of Material. "Micron Scanner" was input as an example with the product item number 10100. Next, we created records for Sales Orders with customer information, sales order items, pricing, expected delivery date, etc. Then, we let the system pass transactions from Sales Orders to the Schedule module so users could create Planned MRP (Material Requirements Planning) Orders. Since there was not sufficient materials to manufacture the sales order items, we initiated a purchase order for the materials needed and then forwarded the information to Purchase and Manufacture modules. In the Purchase module, we used the order from Planned MRP to generate the purchase order and updated the Inventory modules when we received shipment on the required items. Once the Inventory module confirmed receipt, we input a voucher for the received purchased Items and then posted it. Then, in the Accounting module, we issued the payment for the materials needed. At this point, the Manufacture module issued the Work Order materials. Once the Work Order was completed, the Inventory module updated the finished goods and shipped the product. The Sales module then generated an invoice to bill the customer for the goods. When payment was received, the Accounting module debited the money received and updated the general ledger. The system allowed different reports on the account to be printed or displayed if needed.

From this example, we showed students the level of complexity when information was flowing through different processes and was interrelated through an enterprise perspective. Yet, the simple hands-on lab appeared to be helpful in illustrating how an ERP application could help facilitating and supporting business process integration. After going through the hands-on session, students seemed to have a feel of the interconnection among different processes to form an integrated enterprise system. In this case, the trigger was made when the Sales Order was generated. Based on the information from the Sales Order, a Purchase Request was created. It was then sent to two different functions: Purchasing and Production. The two functions took the information from the Purchase Request and carried out the transaction to the completion of the process. This simple illustration showed successfully how xTuple-PostBooks was capable of linking various functions together, coordinating the information flow smoothly, tracking the status of the order, and generating detailed information for review and monitor. These are the reasons why an ERP system such as xTuple-PostBooks can provide valuable experience for students to see how the business processes work and how they are integrated.

\section{Preliminary Results from Students' Perception on the Use of xTuple-PostBooks in Two Classes}

At the end of the session on enterprise systems, we asked students to fill out a web-based survey. The purpose of this survey was to solicit students' opinions, perceptions, and recommendations with regard to the use of xTuple-PostBooks. Seventeen seniors and eleven MBA students took part in the survey. The survey consisted of questions related to four areas: (1) Feedback on xTuple-PostBooks, (2) xTuple-PostBooks' Impact on Learning, (3) Satisfaction, (4) Increase in knowledge and skill of ERP.

Tables 1 and 2 summarize our exploratory findings: 
Table 1: Findings on xTuple-PostBooks' Usability

\begin{tabular}{|c|c|c|c|c|c|}
\hline \multirow[b]{2}{*}{ Questions for xTuple-PostBooks's Experience } & \multicolumn{5}{|c|}{ Response } \\
\hline & 1 & 2 & 3 & 4 & 5 \\
\hline $\begin{array}{l}\text { Your rating on xTuple-PostBooks' User Inter- } \\
\text { face }\end{array}$ & $\begin{array}{c}4 \\
(14 \%)\end{array}$ & $\begin{array}{c}1 \\
(4 \%)\end{array}$ & $\begin{array}{c}16 \\
(57 \%)\end{array}$ & $\begin{array}{c}6 \\
(21 \%)\end{array}$ & $\begin{array}{c}1 \\
(4 \%)\end{array}$ \\
\hline Your rating on xTuple-PostBooks' Ease of Use & $\begin{array}{c}6 \\
(21 \%)\end{array}$ & $\begin{array}{c}3 \\
(11 \%)\end{array}$ & $\begin{array}{c}15 \\
(54 \%)\end{array}$ & $\begin{array}{c}3 \\
(11 \%)\end{array}$ & $\begin{array}{c}1 \\
(4 \%)\end{array}$ \\
\hline $\begin{array}{l}\text { Your rating on xTuple-PostBooks' Functional- } \\
\text { ities }\end{array}$ & $\begin{array}{c}1 \\
(4 \%)\end{array}$ & $\begin{array}{c}3 \\
(11 \%)\end{array}$ & $\begin{array}{c}14 \\
(50 \%)\end{array}$ & $\begin{array}{c}9 \\
(32 \%)\end{array}$ & $\begin{array}{c}1 \\
(4 \%)\end{array}$ \\
\hline $\begin{array}{l}\text { Your rating on xTuple-PostBooks' Navigational } \\
\text { design }\end{array}$ & $\begin{array}{c}3 \\
(11 \%)\end{array}$ & $\begin{array}{c}2 \\
(7 \%)\end{array}$ & $\begin{array}{c}18 \\
(64 \%)\end{array}$ & $\begin{array}{c}4 \\
(14 \%)\end{array}$ & $\begin{array}{c}1 \\
(4 \%)\end{array}$ \\
\hline \multirow{2}{*}{$\begin{array}{l}\text { Questions for xTuple-PostBooks' as a Teaching } \\
\text { Tool }\end{array}$} & \multicolumn{5}{|c|}{ Response } \\
\hline & 1 & 2 & 3 & 4 & 5 \\
\hline $\begin{array}{l}\text { How useful is xTuple-PostBooks for teaching } \\
\text { business process integration? }\end{array}$ & $\begin{array}{c}1 \\
(4 \%)\end{array}$ & $\begin{array}{c}2 \\
(7 \%)\end{array}$ & $\begin{array}{c}9 \\
(32 \%)\end{array}$ & $\begin{array}{c}13 \\
(46 \%)\end{array}$ & $\begin{array}{c}3 \\
(11 \%)\end{array}$ \\
\hline $\begin{array}{l}\text { How useful is xTuple-PostBooks for illustrating } \\
\text { supply chain management? }\end{array}$ & $\begin{array}{c}1 \\
(4 \%)\end{array}$ & $\begin{array}{c}1 \\
(4 \%)\end{array}$ & $\begin{array}{c}7 \\
(25 \%)\end{array}$ & $\begin{array}{c}17 \\
(61 \%)\end{array}$ & $2(7 \%)$ \\
\hline $\begin{array}{l}\text { How useful is xTuple-PostBooks for helping } \\
\text { you understand the concept of ERP in general/ }\end{array}$ & $\begin{array}{c}1 \\
(4 \%)\end{array}$ & $\begin{array}{c}4 \\
(14 \%)\end{array}$ & $\begin{array}{c}12 \\
(43 \%)\end{array}$ & $\begin{array}{c}7 \\
(25 \%)\end{array}$ & $\begin{array}{c}4 \\
(14 \%)\end{array}$ \\
\hline $\begin{array}{l}\text { How useful is xTuple-PostBooks for helping } \\
\text { you develop practical skills in using ERP? }\end{array}$ & $\begin{array}{c}2 \\
(7 \%)\end{array}$ & $\begin{array}{c}3 \\
(11 \%)\end{array}$ & $\begin{array}{c}13 \\
(46 \%)\end{array}$ & $\begin{array}{c}7 \\
(25 \%)\end{array}$ & $\begin{array}{c}3 \\
(11 \%)\end{array}$ \\
\hline \multicolumn{6}{|l|}{1 - Below requirements } \\
\hline \multicolumn{6}{|l|}{2 - Minimum requirements } \\
\hline \multicolumn{6}{|l|}{3 - Meet requirements } \\
\hline \multicolumn{6}{|l|}{$4-$ Above requirements } \\
\hline 5 - Exceeds requirement & & & & & \\
\hline
\end{tabular}

According to the results shown in Table 1, students' perceptions of xTuple-PostBooks were positive in general. Most of them felt that the application had met the requirements in terms of its user interface, ease of use, functionalities, and navigation design. Also, the students' perceptions on the use of xTuple-PostBooks for teaching were quite positive. The hands-on experience with using xTuple-PostBooks seemed to enhance students' learning about business process integration, understanding of supply chain management and concepts of ERP, as well as helping students develop practical skills in using ERP. 
Table 2: Findings on satisfaction with $x$ Tuple-PostBooks and knowledge learned

\begin{tabular}{|c|c|c|c|c|c|}
\hline \multirow{2}{*}{$\begin{array}{l}\text { Satisfaction with xTuple-PostBooks and knowledge } \\
\text { learned }\end{array}$} & \multicolumn{5}{|c|}{ Response } \\
\hline & 1 & 2 & 3 & 4 & 5 \\
\hline $\begin{array}{l}\text { Are you satisfied with learning and using xTuple- } \\
\text { PostBooks as part of this course? }\end{array}$ & $\begin{array}{c}19 \\
(68 \%)\end{array}$ & $\begin{array}{c}5 \\
(18 \%)\end{array}$ & $\begin{array}{c}3 \\
(11 \%)\end{array}$ & $\begin{array}{c}0 \\
(0 \%)\end{array}$ & $\begin{array}{c}1 \\
(4 \%)\end{array}$ \\
\hline $\begin{array}{l}\text { How satisfied are you with the knowledge and skills } \\
\text { gained from learning and using xTuple-PostBooks? }\end{array}$ & $\begin{array}{c}16 \\
(57 \%)\end{array}$ & $\begin{array}{c}5 \\
(18 \%)\end{array}$ & $\begin{array}{c}5 \\
(18 \%)\end{array}$ & $\begin{array}{c}2 \\
(7 \%)\end{array}$ & $\begin{array}{c}0 \\
(0 \%)\end{array}$ \\
\hline $\begin{array}{l}\text { Do you feel that your knowledge and skill of ERP was } \\
\text { increased after learning and using xTuple-PostBooks in } \\
\text { this class? }\end{array}$ & $\begin{array}{c}17 \\
(61 \%)\end{array}$ & $\begin{array}{c}10 \\
(36 \%)\end{array}$ & $\begin{array}{c}1 \\
(4 \%)\end{array}$ & $\begin{array}{c}0 \\
(0 \%)\end{array}$ & $\begin{array}{c}0 \\
(0 \%)\end{array}$ \\
\hline \multicolumn{6}{|l|}{$1-$ Satisfied } \\
\hline \multicolumn{6}{|l|}{2 - Somewhat satisfied } \\
\hline \multicolumn{6}{|l|}{3 - Neither satisfied nor dissatisfied } \\
\hline \multicolumn{6}{|l|}{4 - Somewhat dissatisfied } \\
\hline 5 - Dissatisfied & & & & & \\
\hline
\end{tabular}

In terms of students' satisfaction, the evidence (as shown in Table 2) was again quite positive. Most of the responses indicated that students were satisfied or somewhat satisfied with the use of xTuple-PostBooks as well as the outcome.

\section{Discussion}

Based on the observation of students' interaction in class as well as the feedback from student users, the use of xTuple-PostBooks appeared to have a positive impact in the learning of business process integration. One, xTuple-PostBooks is not too complicated as a teaching tool. Its interface, functionalities, and navigational design are manageable for an average student regardless of his/her major. Two, xTuple-PostBooks seems to enhance student's comprehension of how various business processes are integrated and related in the example. Finally, students in general were satisfied with their use of xTuple-PostBooks. Hence, for the purpose of evaluation and teaching an ERP system, we would recommend xTuple-PostBooks because of its ease of use, comprehensive documentation, rich resources, and sound illustration of an integrated business process facilitated by an ERP application. As described previously, the use of xTuple-PostBooks can provide a variety of benefits in teaching business process integration. Among the most important benefits is the opportunity it gives for students to observe firsthand the integration of knowledge across functional areas in a timely manner.

For example, suppose the students are studying the business model for a retail store. Without an ERP system they might be asking very general questions such as: What is the profit margin for an item? What is the percentage of profit contribution of an item? These questions may be answered without an ERP system, but the process will be time-consuming and manual computational mistakes may occur. With an ERP system, one can obtain these answers very quickly, so the students will save time, and the logic of the system is more likely to be correct.

From our experience, xTuple-PostBooks is a very promising open-source ERP system that can be integrated for teaching about enterprise systems in core business classes. However, the faculty who intend to incorporate xTuple-PostBooks may need to spend significant time on development 
of appropriate content. The current demo may be appropriate for first-time users and for an introduction to computer information systems classes. For higher-level course work, however, students will need to create their own company, set up data, carry out transactions, and analyze more business models that the demo does not show.

\section{Practical Implications}

Since there are only a relatively small number of open-source ERP vendors in the market, there are several issues of which a potential adopter of an open-source ERP system should be aware. One is the lack of a clear business model for an open-source ERP vendor to deal with educational institutions. For most open-source ERP vendors, their main clients are businesses, not educational institutions. Should the educational institutions be end-user clients or partners? How much should the educational institutions get charged when their main use of the software is mainly for teaching and learning purposes, not for revenue-generating as in the case of business users? Other issues to take into account are that there are only a few developers, few resources available, and unknown costs when dealing with open-source software.

Therefore, when one decides to adopt open-source ERP software, it is recommended that the adopter look beyond the license cost. Although it is free to download the open-source software, there are potentially other costs including training, maintenance, roll-out costs, and unknown risks. Also, it is important to take a careful look at the vendor that will support a chosen opensource ERP. Vendor viability and the product's development roadmap will be important for support, enhancement, and upgrade down the road (Roberts, 2009). One needs to evaluate opensource ERP software the same way as any other commercial software application. It is important to know what the needs are and how they can be met.

\section{Conclusion}

This paper describes two approaches in bringing ERP into the classroom. One is to join the SAP University Alliances program. This is a well-established program and is backed by SAP, Inc., one of the world's biggest ERP software vendors. The program provides many valuable resources and offers easy access to SAP's latest ERP application suites. The knowledge and experience for integrating SAP into a business curriculum are available and have been documented in IS literature. Therefore, the SAP University Alliances program is certainly a good choice.

However, in today's economic hard times, obtaining the necessary funding and securing longterm support to join the SAP University Alliances program can be a big challenge, especially at those schools undergoing severe budget reductions. The alternative to the SAP University Alliances program is to explore the open-source ERP option. This paper described our experience with one specific product called xTuple-PostBooks. We believe that it is feasible to adopt an open-source ERP system, install and deploy it for the purpose of teaching.

One of the challenges in adopting xTuple-PostBooks is perhaps the steep learning curve. Unlike the SAP University Alliances program, one needs to set up both the hardware and software. It requires working knowledge on a server operating system, xTuple-PostBooks software installation and operation. However, the information and experience presented in this study would help to lessen the learning curve. In addition, we also made the detailed notes on the installation and setup of xTuple-PostBooks available on the web. All of these will save much time for those who are interested in trying out xTuple-PostBooks. The more users experiment with the software, the more knowledge will result. Each lesson learned and shared will help reduce the learning curve further and thus make xTuple-PostBooks even more attractive as an alternative to SAP.

Although one of the major incentives for adopting open-source software is the absence of license fees, the experience that we had with xTuple-PostBooks shows that it has a great potential as a 
teaching tool. xTuple-PostBooks is not only affordable, but also accessible. Anyone can implement it at minimum cost. Using xTuple-PostBooks opens an interesting possibility for small and mid-sized local organizations. To many of them, the cost of using SAP is prohibitive. xTuplePostBooks can provide the capability to meet the needs of many local organizations especially those in non-profit sector. Teaching supply chain management with xTuple-PostBooks may open opportunities for potential partnerships with these entities.

Supply chains are becoming transparent and have become global. Standardization of softwarebased web services and service-oriented architecture will be the primary platform on which large as well as small enterprises compute and communicate. The result will be an increase in the demand for workers with skills in enterprise systems such as ERP. The information and communications industry (ICT) requires a broad range of skills (Department of Infrastructure, 2003). The shortage of ERP skills is not a recent phenomenon. People with ERP skills are in short supply and are experiencing rapid changes in their market value. In accordance with this demand, there is a value in incorporating ERP into the supply chain management curriculum. More importantly, using ERP at the core of teaching supply chain management can fill the gap between theory and practice. It can help bring relevance to practice and to professional careers and hence may help prepare students for successful careers in the area of supply chain management. This can be achieved with renewed curriculum that has a balanced mixture of soft skill and hard skill learning. Furthermore, business schools should also explore innovative ways of pre-training entry level ERP professionals through internships or other means of partnering with the industry as suggested in McMurtrey, Downey, Zeltmann, and \& Friedman's study of critical skill sets of entrylevel IT professionals (2008).

\section{Limitations and Future Directions}

This study has several limitations. First of all, while we described the problem of the introduction of open-source ERP in university education and assessed the impact on students' learning, we limited our discussion to the tutorial systems and could not compare it with the proprietary system in everyday teaching or contrast it with the simulation of concrete situations. Secondly, our experiences with teaching xTuple-PostBooks focused mainly on the tutorial examples offered by xTuple. This is rather narrow in scope. How should xTuple-PostBooks be incorporated into other courses and/or into the curriculum? Would it be useful to a capstone information systems class for an IS major? Questions on how xTuple-PostBooks should be integrated remains unknown and needs to be discussed in the future. Thirdly, because we chose to focus mainly on xTuplePostBooks and did not cover other ERP applications, the results might not be generalizable. Although this might reflect our biased view, xTuple-PostBooks is the only software we have experiences with. Finally, the survey from the students is currently used for feedback purpose to improve the course integration process. The sample is too small to yield any statistical implications at this time.

In this paper we attempted to present our first step in setting up and trying out with xTuplePostBooks. For follow-up work, we plan to design a more robust case based on xTuplePostBooks. This case will feature a fictitious company selling laptop PCs. We plan to illustrate steps involved in various business processes, set up data flowing through these processes, and carry out various tasks through xTuple-PostBooks. In the next phase, we hope to implement xTuple-PostBooks in a real-world setting. Our focus will be on non-profit organizations. We will invite a local non-profit agency to participate and try out xTuple-PostBooks. We will help this agency with the setup and technical support. In return, we will use it as a study site to explore how a real-world organization is using xTuple-PostBook to support its operations. 


\section{References}

Andriole, S., \& Roberts, E. (2008). Point/counterpoint technology curriculum for the early $21^{\text {st }}$ century. Communications of the ACM, 51(7), 27-30.

Caruso, D. (2009). 4 ways an integrated ERP system improves supply chain performance. Retrieved $19^{\text {th }}$ September, 2009, from http://www.microsoft.com/dynamics/en/us/industries/manufacturing-erpsupply-chain.aspx

Conlon, M. P. (2007). An examination of initiation, organization, participation, leadership, and control of successful open-source software development projects. Information Systems Education Journal, 5(38). Retrieved from http://isedj.org/5/38/

Conlon, M. P., \& Hulick, F.W. (2006). Is there a role for open source software in systems analysis? Information Systems Education Journal, 4(88). Retrieved from http://isedj.org/4/88/

Corbitt, G., \& Matthews, H. (2009). University alliance program: Bird's eye view of UA in North America. Retrieved $12^{\text {th }}$ July, 2011, from http://www.sdn.sap.com/irj/uac/go/portal/prtroot/docs/library/uuid/f08809dc-c6b2-2c10-1c98ad9e37224973?QuickLink=index\&overridelayout=true

Department of Infrastructure. (2003). ICT Skills Snapshot: The state of ICT skills in Victoria. Melbourne, Australia.

Hawking, P., Bassett, P., \& Foster, S. (2002). An applied approach to teaching HR concepts using an ERP system. Proceedings of Informing Science Conference 2002, Ireland: Cork. Retrieved from http://proceedings.informingscience.org/IS2002Proceedings/papers/Hawki128Appli.pdf

Hawking, P., \& McCarthy, B. (2004). Integrating e-learning into enterprise resource planning (ERP) curriculum. Journal of Issues in Informing Science and Information Technology, 1, 23-30. Retrieved from http://informingscience.org/proceedings/InSITE2004/014hawki.pdf

Hawking, P., McCarthy, B., \& Stein, A. (2004). Second wave ERP education. Journal of Information Systems Education, 15(3), 327-332.

Hayes, G., \& McGilsky, D. (2007). Integrating an ERP system into a BSBA curriculum at Central Michigan University. International Journal of Quality and Productivity Management, 7(1), 12-27.

Johnson, T., Lorents, A., Morgan, J., \& Ozmun, J. (2004). A customized ERP/SAP model for business curriculum integration. Journal of Information Systems Education, 15(3), 245-254.

Kesner, R. (2008). Business school undergraduate information management competencies: A study of employer expectations and associated curricular recommendations. Communications of the Association for Information Systems (CAIS), 23, 634-654.

Lee, H., Chen, K. L., \& Yang, J. (2006). Teaching enterprise resource planning (ERP) systems in the supply chain management course. Communications of the IIMA, 6(3), 77-85.

Léger, P., Charland, P., Feldstein, H., Robert, J., Babin, G., \& Lyle, D. (2011). Business simulation training in information technology education: Guidelines for new approaches in IT training. Journal of Information Technology Education, 10, 39-53. Retrieved from http://www.jite.org/documents/Vol10/JITEv10p039-053Leger914.pdf

Lemos, R. (2008, April 22). Open-source ERP grows up. InfoWorld. Retrieved $31^{\text {st }}$ July, 2011, from http://www.infoworld.com/t/applications/open-source-erp-grows-615

Madapusi, A. (2007). Using ERP to bridge the POM Academia-industry divide. Proceedings of AIS SIGED: International Academy of Information Management Annual Conference 2007.

McMurtrey, M., Downey, J., Zeltmann, S., \& Friedman, W. (2008). Critical skill sets of entry-level IT professionals: An empirical examination of perceptions from field personnel. Journal of Information Technology Education, 7, 101-120. Retrieved from http://www.jite.org/documents/Vol7/JITEv7p101120McMurtrey312.pdf 
Peslak, A. R. (2005). A twelve-step, multiple course approach to teaching enterprise resource planning. Journal of Information Systems Education, 16(2), 147-155.

Porter, L., \& McKibbin, L. (1998). Management education and development: Drift or thrust into the 21st century? New York, NY: McGraw-Hill.

Roberts, B. (2009, March). Open-source solutions for HR. HR Magazine, 69-73.

Seethamraju, R. (2007). Enterprise systems (ES) software in business school curriculum: Evaluation of design and delivery. Journal of Information Systems Education, 18(1), 69-84.

Wang, M., \& El-Masry, E. (2009). Assessments and outcomes of an ERP/SAP fundamentals course. Issues in Information Systems. 10(1-2), 109-114.

Winkelmann, A., \& Leyh, C. (2010, Summer). Teaching ERP systems: A multi-perspective view on the ERP system market. Journal of Information Systems Education, 21(2), 233-242.

\section{Biographies}

Minh Q. Huynh is an Associate Professor of MIS at Southeastern Louisiana University. He received his Ph.D. from State University of New York at Binghamton. His teaching expertise is in

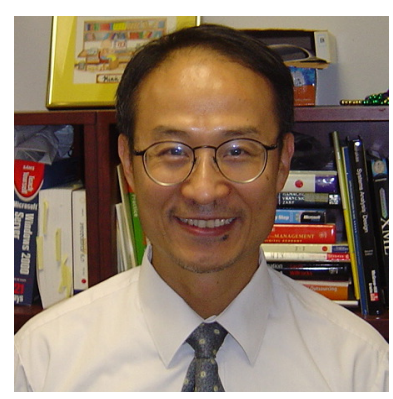
the area of E-commerce, database management, decision support systems, and emerging technology. Research interests include IS outsourcing, IS integration, enterprise systems, open source software, IS in small-medium enterprises, and E-learning. His publications appear in such journals as the Communications of ACM, Journal of AIS, Communications of AIS, European Journal of IS, Journal of Electronic Commerce in Organizations, International Journal of E-Business Research. Prior to his academic career, he had worked in the areas related to computer programming, systems management, technical support, and network security.

Hung W. Chu is an Adjunct Assistant Professor of Management for the Zicklin School of Busi-

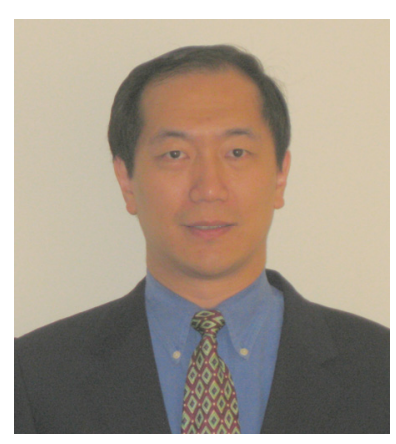
ness at Baruch College. Dr. Chu holds a B.E. degree from Cooper Union, M.E. degree from City College of New York, M.B.A. degree from Baruch College, and Ph.D. degree from City University of New York. His teaching expertise is in the area of operation management as well as strategic management. His current research interests are in the areas of information resource management, information system implementation strategies, mergers and acquisitions integration, supply chain management, application of resource based theory, and behavior of Chinese enterprises. He had programming experience with government, not-forprofit, and for profit institutions. 